\title{
Hybrid Learning versus Traditional Course in Mathematics Classroom for Higher Education: Students' Achievement and Students' Experiences
}

\author{
Rudianto Artiono \\ Mathematics Department \\ Universitas Negeri Surabaya \\ Surabaya, Indonesia \\ rudiantoartiono@unesa.ac.id
}

\author{
Yuliani Puji Astuti \\ Mathematics Departmnet \\ Universitas Negeri Surabaya \\ Surabaya, Indonesia \\ yulianipuji@unesa.ac.id
}

\author{
Mega Teguh Budiarto \\ Mathematics Department \\ Universitas Negeri Surabaya \\ Surabaya, Indonesia \\ megatbudiarto@unesa.ac.id
}

\begin{abstract}
This study aimed to examine the outcome of lectures conducted using hybrid learning in Integral Calculus courses. It focused on students' achievement and students' experiences. Teaching materials were developed using the Plomp development model in the form of learning videos which met valid, practical and effective criteria. While the data analysis techniques were carried out by quantitative-descriptive and qualitative-descriptive methods. The results showed that students' learning achievement increased significantly using hybrid learning compare to traditional course. A number of students have met the mastery learning criteria. Regard to students' experiences, some students felt that lectures conducted using hybrid learning were easier to understand because the video could be played repeatedly. It helped student to understand the material. It also gave freedom for students to determine time and place. Unfortunately, some students revealed that the implementation of lectures using hybrid learning also had disadvantages.
\end{abstract}

Keywords-Hybrid Learning, Traditional Course, Students' Achievement, Students Experiences

\section{INTRODUCTION}

Over the past 10 years, technology has changed the behavior and civilization of people throughout the world. This change also affects the learning process that occurs in classes both at the elementary school level to the university level. At present, almost all schools have used technologybased learning media to deliver teaching materials. In addition, if schools previously conducted national examinations using paper and pencil test, the Indonesian government since 2014 has pioneered the implementation of computer-based national examinations. Another support from the Government for the use of technology in education is the making of Republic of Indonesia Government Regulation no 74 of 2008 article 3 paragraph 4 specifically which explains that the pedagogical ability of a teacher is the ability in managing student learning, one of which uses learning technology. This indirectly requires the teacher to be able to interact with technology during the teaching and learning process. This is also not much different from a lecturer in a college. A lecturer is also required to be able to utilize technology during the lecture process.

One form of technology utilization in education is the implementation of lectures using E-Learning. This process is also known as an online learning process. E-Learning is defined as a learning process carried out using electronic devices [1]. More specifically, Abbad stated that E-Learning is a teaching and learning process that is carried out using digital technology. While some other researchers define ELearning as any learning that is supported by the internet or web-based [2, 3]. Lectures conducted using E-Learning can provide a quality learning experience for students with the use of internet technology as a medium of learning.

From the standpoint of educational theory which is quite well known today, namely: Theory of Behaviorism and Constructivism Theory, the use of E-Learning in student lectures has been able to integrate the two theories. Behaviorism Theory which states that the learning process is a change in behavior that is a response from a stimulus [4]. This applies when students attend lectures using E-Learning. Changes in student behavior so far only as objects in class can be changed to the subject of each lecture with access given during lectures using E-Learning. Likewise in constructivism theory where the knowledge gained in the learning process is built based on the experience gained from the previous learning process. A student can build his own understanding through the materials delivered in lectures using E-Learning.

Implementation of lectures using E-Learning can be divided into several types when viewed from the proportion of the number of meetings between lecturers and students. According to Pramono et al. [5], the type of E-Learning lectures when viewed from the proportion of the amount of face-to-face is distinguished as follows.

a. Traditional face-to-face ( $0 \%$ online). In this type of lecture, lecturers have not used E-learning lectures. Lectures use traditional methods where students still use printed and oral teaching materials. Lectures are conducted in the classroom with lecturers as subjects and students as objects. 
b. Web-Enhanced $(1 \%-29 \%)$. This type of lecture takes place when the lecturer has used internet technology to support the lecture. The internet is used only to facilitate faceto-face patterns or the use of websites in posting certain grades or tasks.

c. Blended/Hybrid (30\%-79\%). This type is a lecture that combines online methods with traditional methods (face to face). There is a proportion of the delivery of teaching material that is done online accompanied by a discussion forum to discuss teaching material that is being discussed. In this type, the number of face-to-face meetings is reduced by online meetings held on the internet.

d. Fully Online (80\%). This type of lecture is delivered entirely online, without any face-to-face portions at all.

Lectures using internet technology assistance are initiated by the teacher or lecturer who prepares teaching materials such as Learning Designs, PowerPoint, Learning Videos, practice questions and assignments which are then uploaded to the website pages that have been prepared, while students are given access to be able to download all teaching materials needed during the lecture process.

This study examines the outcome of lectures conducted using hybrid learning in Integral Calculus courses. It was only focused on students' achievement and students' experiences after hybrid learning process was given to the student. In this study, two research questions are investigated that address this connection: 1) how do students' achievement relate to hybrid learning and 2) how do students' experiences relate to hybrid learning?

\section{HYBRID LEARNING}

According to Thorne, hybrid Learning is the most logical evolution that develops naturally from a teaching and learning process that is influenced by technological advances [6]. Hybrid Learning has been able to answer the challenges and opportunities for the development of innovations that are integrated with technology in the world of education. Meanwhile, Umoh et al define Hybrid Learning as a combination of various learning media that involves technology, activities, and various ways to create optimal learning programs for special students [7]. The term "combination" means that training led by a teacher is equipped with other electronic formats. In this context, combined learning programs use various forms of e-learning.

Today, the term hybrid is increasingly popular in the community to describe something that is mixed, this also results in the use of the word to combine learning strategies that use face-to-face with learning that is done offline and online. Thus, hybrid learning can be defined as learning that combines the delivery of learning strategies using face-toface activities, computer-based learning (offline), and computer online (internet). This learning developed around 2000 and now it is widely used in several countries such as North America, the United Kingdom, and Australia, especially among universities and the training world. At several universities in the UK, there is a consortium of mathematics majors that conduct online lectures for doctorallevel students. This can be seen on the consortium's website, https://maths-magic.ac.uk.
The main purpose of hybrid learning is to provide opportunities for a variety of learner characteristics to create independent, sustainable, and lifelong learning patterns so that the essence of learning will be more effective, more efficient, and more interesting.

According to Henrich and Sieber [8], there are several characteristics of hybrid learning, including:

a. Learning that combines various ways of delivery, teaching models, learning styles, as well as a variety of diverse technology-based media

b. As a combination of direct teaching (face-to-face), independent learning, and independent learning offline and online.

c. Learning is supported by an effective combination of ways of delivery, ways of teaching and learning styles.

d. The teacher and parent have the same important role, the teacher as a facilitator, and the parent as a supporter.

While Rosset et al [9] suggest 6 things to consider when implementing the teaching and learning process using hybrid learning. These six things can be described as follows.

a. Submission of teaching materials and delivery of other messages (such as announcements) must be done consistently. This can be interpreted that, if during the lecture planning has been delivered about the existence of tasks that must be completed within a certain period, then through hybrid learning the plan must be done in accordance with what has been planned. If at the beginning of the lecture it has been said that there is a discussion forum to discuss the material being asked, then when questions are available in the forum then it is obligatory for lecturers to provide answers to these questions.

b. Organizing learning through hybrid learning must be carried out seriously. This can be interpreted that if a lecturer has planned to conduct lectures on a hybrid learning basis, then the lecturer is required to carry out lectures in this manner. A lecturer cannot convey a lecture plan using blended learning but then at the agreed time then cancels the implementation of the lecture using hybrid learning.

c. The teaching material given must always be improved (update) both the format, its contents, and the availability of teaching materials that meet the rules of independent teaching materials. Considering the teaching material used in this hybrid learning will be uploaded on the internet and everyone can see this teaching material, then the instructional material used should always be updated so that no concept errors are found either due to errors from the library sources and errors in typing.

d. Time allocation can begin with the 75:25 formula in the sense that $75 \%$ for online learning and $25 \%$ for face-toface (conventional) learning or vice versa. This can be understood as an effort to form a new culture for learners to get used to learning independently without the need for the presence of a teacher in the classroom.

e. Tutorial time allocation is $25 \%$ specifically for those who are left behind, but if it is not possible then that time can be used to solve students' difficulties in understanding learning problems. One of the advantages of hybrid learning is that there are no limitations on time and space so that if a person who has difficulty understanding teaching material is found, it is still 
possible for that person to consult specifically with the instructor.

f. In hybrid learning, leadership is needed that has the time and attention to continuously strive to improve the quality of learning. This is necessary to improve the quality of learning carried out using hybrid learning.

Before carrying out the teaching and learning process using hybrid learning, there are several steps that must be taken so that learning can proceed as planned. The following are the steps that can be taken in preparing for lectures using hybrid learning.

a. Identifying courses to be developed with hybrid learning, for example in this study, researchers chose a calculus integral course.

b. Identifying the ability of students who will program courses to be delivered using hybrid learning. One of these abilities is the ability of students to interact with technology.

c. Arrange Semester Learning Plan (RPS) which contains the implementation of lectures using hybrid learning.

d. Make the content output in accordance with the RPS that has been prepared. This can be in the form of modules, powerpoints, or learning videos.

\section{RESEARCH METHOD}

This research was conducted in integral calculus courses in the even semester of the academic year 2018/2019. The research subject were 45 students who took the course. From 16 weeks of face-to-face meetings, it took 3 weeks for the implementation of hybrid learning by taking material on integration techniques using the substitution method, Integral Rational Functions, and Partial Integral. The implementation of hybrid learning began with the creation of online classes on Unesa's virtual learning website. Furthermore, teaching materials were developed to support hybrid learning in the form of learning videos, practice questions, and power points. All teaching materials was developed by following the Plomp development model which consists of five phases: (1) initial investigation phase, (2) design phase, (3) realization phase, (4) test, evaluation and revision phase, (5) implementation phase.

After obtaining teaching materials that met the valid, practical, and effective criteria, instructional materials were then included on Unesa's virtual learning website and opened access for students to be able to download teaching materials and uploaded student work. In addition, a research tool in the form of questionnaire was also developed to see the learning experiences of students during learning process using hybrid method. This questionnaire could be accessed by students at the end of the third meeting to find out student learning experiences.

The data obtained in this study consisted of student learning outcomes which collected through student assignments and student learning experience which collected through questionnaires. At the end of each meeting, students were asked to do assignments that are in accordance with the material being taught. Furthermore, the results of these student assignments were used as indicators of student learning success. Meanwhile, students' learning experience related to satisfaction using hybrid learning process was taken after three weeks of implementing hybrid learning.

\section{RESULTS AND DISCUSSION}

Based on the results of expert validation, the developed teaching material, namely: powerpoint and learning video can be stated to meet the construct validity criteria and can be used with a little revision. In addition, according to the results of the validation the expert of this teaching material also meets the content validity criteria and can be used with a slight revision.

Furthermore, to answer research questions about learning outcomes and the learning experiences of students who take lectures with hybrid learning, researchers conducted an analysis of the mathematics learning outcomes of 2018 class students in integral calculus courses. Student learning outcomes data is carried out using four components, namely; Student participation scores $(=\mathrm{P})$, average assignment scores $(=\mathrm{T})$, sub-summative exam results (= USS) and summative exam results (= US), while the student's final grade (=NA) is determined using the formula: then the final grade is converted to the graduation criteria of a course. From the data obtained, it can be stated that student learning outcomes in differential calculus are said to be good because the percentage of students who get a minimum grade of $\mathrm{B}$ is $76.00 \%$ (more than $70 \%$ ).

Based on the processing of questionnaire results about student learning experiences, it can be stated that the mathematics class of 2018 students who program integral calculus courses have a positive response. This can be seen from the results of a questionnaire which states that more than $50 \%$ of students gave a positive response to $100 \%$ of the aspects in question. In addition, the average score for all questionnaire results was more than 2.50 (100\% of the questionnaire items received a positive response).

Some students said that hybrid learning gave them more freedom to access course material anytime and anywhere. They also said that hybrid learning took place effectively because students could focus on their own learning and could repeat materials which were not clear through learning videos. Other students added that they have a better understanding of how to determine the integral of a function. They asked to use this learning method for other subjects. There was one student who said that he did like technology so that when the lectures were done using technology, he got more excited. While another student also said that he could immediately discuss with friends when he had difficulty in understanding lecture material through learning videos. One student also said that he enjoyed hybrid learning because he didn't have to come to the class to get lecture material.

There were some suggestions from students about hybrid learning. They recommend that lectures using hybrid learning also be applied to other courses. Students should be given training in advance about how to interact with online learning media. Another suggestion was the concept of learning based on hybrid learning can be made for 16 meetings, although not all lecture material must be submitted online. They also suggested that forum discussion should be available in online classes so that communication between lecturers and students would be maintained very well.

From some of these positive responses, data are still obtained about the weaknesses of hybrid-based learning, for 
example, some students still want the presence of a lecturer in the class. The weakness of the internet network on campus, so that students find it difficult to view learning videos without the buffering process. Another bad response from student was about not all students have a personal laptop, while the number of computer facilities provided by the department is limited and is used by all students in the mathematics department.

\section{CONCLUSION}

The results showed that students' learning achievement increased significantly using hybrid learning compare to traditional course. A number of students have met the mastery learning criteria. Regard to students' experiences, some students felt that lectures conducted using hybrid learning were easier to understand because the video could be played repeatedly. It helped the student to understand the material. It also gave freedom for students to determine time and place. Unfortunately, some students revealed that the implementation of lectures using hybrid learning also had disadvantages.

\section{REFERENCES}

[1] Abbad, E-Learning is defined as a learning process carried out using electronic devices, 2009.

[2] R. LaRose, J. Gregg, and M. Eastin, "Audio graphic tele-courses for the Web: An experiment," Journal of Computer Mediated Communications, 4(2), 1998

[3] C. Keller and L. Cernerud, "Students' perception of e-learning in university education.Learning," Media and Technology, 27(1), pp. 5567. 2002.

[4] B. F. Skinner, About Behaviorism. New York: Vintage Books, 1976.

[5] M. Pramono, M.S. Prastiwi, M. Sumbawati, S.C. Wibowo, Sukarmin, Salamun, and W. Yustanti, Pedoman Penyelenggaraan Kuliah Daring di Unesa, Universitas Negeri Surabaya, 2018.

[6] K. Thorne, Blended Learning: How to integrate online and traditional learning, London: Kagan Page, 2003

[7] J. Umoh and E. Akpan, "Challenges of Blended E-Learning Tools in Mathematics: Students' Perspectives University of Uyo," Journal of Education and Learning, 3, 2014.

[8] A. Henrich and S. Sieber, "Concepts of Blended Learning for Different Content Types," Workshop on Blended Learning, pp. 150-161. Edinburgh. 2007.

[9] A. Rossett, F. Douglis, and R. V. Frazee, "Strategies for Building Blended Learning," 2004, Retrieved April 30, 2018 